\title{
Fluid removal by haemofiltration in diuretic resistant cardiac failure
}

\author{
STEPHEN H MORGAN, MARTIN A MANSELL, F DEREK THOMPSON \\ From St Paul's Hospital and Institute of Urology, London
}

SUMMARY A 60 year old woman with diuretic resistant cardiac failure was treated with intermittent haemofiltration before tricuspid valve replacement. This technique can remove large quantities of fluid rapidly, thus controlling oedema and allow appropriate fluid replacement. Haemofiltration is thus a simple and safe method of managing unresponsive oedema in cardiac failure sometimes allowing corrective cardiac surgery.

Some patients with severe cardiac disease continue to suffer from disabling pulmonary and peripheral oedema despite treatment with large doses of diuretic, inotropic, and vasodilative agents. Although the prognosis for such patients is often poor, life may be prolonged if the oedema can be relieved, allowing the patient to undergo definitive surgery. We report the use of intermittent haemofiltration for fluid removal in a patient with intractable cardiac failure.

\section{Case report}

A 60 year old housewife had diuretic resistant cardiac failure secondary to rheumatic heart disease. She had made an apparently complete recovery from an attack of rheumatic fever at the age of 13 years and was asymptomatic until left ventricular failure developed during pregnancy 10 years later. The cardiac failure responded to conventional treatment and the pregnancy continued successfully to term, after mitral valve disease had been diagnosed. Apart from minimal exertional dyspnoea she remained well for the next 15 years and required no treatment. Diuretics were prescribed after congestive cardiac failure had developed and cardiac catheterisation showed mixed mitral and aortic valve disease. By 1980 these symptoms had progressed and she underwent mitral valve replacement, aortic valvotomy, and tricuspid annuloplasty, which produced a pronounced initial improvement in her symptoms. Subsequently, however, she developed increasingly severe tricuspid regurgitation with dyspnoea at rest, hypotension (blood

Requests for reprints to Dr S H Morgan, Division of Inherited Metabolic Diseases, Clinical Research Centre, Northwick Park Hospital, Watford Road, Harrow, Middlesex HAl 3UJ. pressure $90 / 50 \mathrm{~mm} \mathrm{Hg}$ ), and gross ascites, despite treatment with large doses of frusemide, amiloride, and metolazone. Several episodes of malaena occurred, which were thought to be due to mesenteric venous congestion, and her haemoglobin fell to $7 \mathrm{~g} / \mathrm{dl}$. Renal function was impaired with a plasma creatine concentration of $450 \mu \mathrm{mol} / \mathrm{l}$, a blood urea concentration of $20 \mathrm{mmol} / \mathrm{l}$, and a creatinine clearance of 20 $\mathrm{ml} / \mathrm{min}$. Since she was too ill to undergo invasive cardiac investigations or cardiac surgery a decision was taken to correct her fluid overload by intermittent haemofiltration.

\section{INTERMITTENT HAEMOFILTRATION}

The right subclavian vein was cannulated by the Seldinger technique and a high flow dialysis catheter (Vas-cath, Gambro) was inserted and tunnelled beneath the skin. Blood was pumped at approximately $100 \mathrm{ml} / \mathrm{min}$ with a Sarns blood pump and extracorporeal blood lines through a $0.2 \mathrm{~m}^{2}$ haemolfilter (Amicon 20) and returned to a peripheral vein. Clotting of the haemofiltration circuit was prevented by a bolus dose of heparin (2000 IU) given at the start of the procedure.

Haemofiltration was performed for four hours, removing $1200 \mathrm{ml} / \mathrm{h}$, during which time pulse and blood pressure showed no significant change and arterial oxygen content increased from $8.0 \mathrm{kPa}$ to 10.0 $\mathrm{kPa}$. The procedure was repeated on two successive days with a net weight loss of $7 \mathrm{~kg}$, and the patient was transfused up to a haemoglobin of $12 \mathrm{~g} / \mathrm{dl}$. Her clinical condition improved considerably and was accompanied by a pronounced reduction in cardiac size on chest radiograph. Cardiac catheterisation was therefore undertaken and confirmed the diagnosis of tricuspid regurgitation. A routine tricuspid valve 
replacement was performed, which was complicated by postoperative oliguria requiring supportive haemodialysis for two weeks. The oliguria resolved steadily, and at the time of discharge she was free of oedema and taking no diuretics; her creatinine clearance was $60 \mathrm{ml} / \mathrm{min}$.

\section{Discussion}

Diuretic resistant oedema may be a serious problem in patients with cardiac failure. Peritoneal dialysis to remove fluid in these patients has been used for many years. ${ }^{1}$ The efficiency of fluid removal is, however, poor, and in a patient with already compromised ventilatory function the splinting effect on the diaphragm may be detrimental. Haemodialysis is more efficient but is likely to be associated with life threatening arrhythmias and hypotension. In 1947, Alwall described the principle of ultrafiltration, ${ }^{2}$ and its application to oedematous states was further explored by Silverstein et al. ${ }^{3}$

Isolated ultrafiltration relies on the circulation of blood through a conventional haemodialyser containing a Cuprophan membrane, with water and solutes being driven across it by hydrostatic pressure as in the human glomerulus. There is no contact with the dialysate. Although ultrafiltration is accompanied by less circulatory disturbance, complement activation still occurs. This results in leucocyte and platelet aggregation, which may cause pulmonary microembolisation and severe hypoxaemia.

With the development of complex biocompatible membranes made of polycarbonate, the technique of haemofiltration became possible. Unlike the Cuprophan membrane used in ultrafiltration, these newer membranes have an extremely high permeability to water and solutes and produce minimal leucocyte and platelet clumping. ${ }^{4}$ The potential advantages of haemofiltration and ultrafiltration in the management of acutely ill oliguric patients were quickly realiseds and also applied to the correction of hypertension and fluid overload in chronic renal failure. ${ }^{6}$
The extracorporeal circuit for haemofiltration is quick and easy to establish. If one of the lines is placed in an artery a blood pump is unnecessary, thus reducing the potential risks of haemorrhage and air embolism. Our experience with this technique now extends to over 30 patients, in whom no serious complications of the procedure have occurred. These patients had developed acute fluid overload either because of acute renal failure or because of underlying cardiovascular disease. Intermittent haemofiltration was used to control pulmonary oedema, improve oxygenation, and make intravascular space for the administration of intravenous antibiotics, inotropic agents, blood products, or parental nutrition. We have also successfully used haemofiltration during orthotopic cardiac transplantation to remove pulmonary and peripheral oedema, as described previously during cardiopulmonary bypass. ${ }^{7}$

\section{References}

1 Cairns KB, Porter GA, Kloster FE, Bristow JD, Griswold HE. Clinical and hemodynamic results of peritoneal dialysis for severe cardiac failure. Am Heart $\mathcal{F}$ 1968; 76: 227-34.

2 Alwall $N$. On the artificial kidney. 1. Apparatus for dialysis of the blood in vivo. Acta Med Scand 1947; 128: 317-25.

3 Silverstein ME, Ford CA, Lysaght MJ, Henderson LW. Treatment of severe fluid overload by ultrafiltration. $N$ Engl f Med 1974; 291: 747-51.

4 Kramer P, Kaufhold G, Grone HI, et al. Management of anuric intensive care patients with arteriovenous hemofiltration. Int $\mathcal{F}$ Artif Organs 1980; 3: 225-30.

5 Kramer P, Seegers A, de Vivie R, Trautmann M, Scheler F. Therapeutic potential of haemofiltration. Clin Nephrol 1979; ii: 145-9.

6 Quelhorst E, Rieger J, Doht B, et al. Treatment of chronic uraemia by an ultrafiltration kidney-first clinical experience. Proc Eur Dial Transplant Assoc 1976; 13: 315-21.

7 Darup J, Bleese N, Kalmar P, Lutz G, Pokar M, Polonius MJ. Hemofitration during extracorporeal circulation [EEC]. Thorac Cardiovasc Surg 1979; 27: 227-30. 